\title{
A formação pedagógica no ensino superior e o papel da pós-graduação stricto sensu
}

Guilherme Torres Corrêa'

Victoria Maria Brant Ribeiro"

\section{Resumo}

Desenvolvemos este trabalho com base na ideia de que ser docente no ensino superior não é apenas uma questão de domínio de conteúdo, de expertise em determinado campo. A prática pedagógica em tal nível de ensino é complexa, contextualizada, muitas vezes imprevisível e se configura por escolhas éticas e políticas. Nesse sentido, entendemos que a docência demanda um processo formativo que pode ter como fase inicial a pós-graduação stricto sensu. A partir de tal discussão, estabelecemos como objetivo estudar o modo como a formação pedagógica é tratada no âmbito das políticas públicas para o ensino superior, mais especificamente no que tange à pós-graduação stricto sensu. Para tanto, valemo-nos de dois referenciais metodológicos: a teoria dos campos de Pierre Bourdieu e a análise crítica do discurso de Norman Fairclough. A compreensão da pós-graduação como um campo científico e a análise do Plano Nacional de Pós-Graduação indicaram que esse nível de formação superior está basicamente voltado para a acumulação de capital científıco e para a formação de habitus científico, tudo isso em meio a um silêncio sobre a dimensão do ensino no fazer e ser docente. Concluímos que há a necessidade de desenvolver uma cultura de valorização do ensino na universidade, processo este que pode ter na valorização de um capital pedagógico e na formação de um habitus pedagógico na pós-graduação stricto sensu uma fase de grande relevância.

\section{Palavras-chave}

Formação pedagógica - Formação docente - Docência no ensino superior - Pós-graduação.

I- Universidade de São Paulo, São Paulo, SP, Brasil. Contato: correa.gt@usp.br

II- Universidade Federal do Rio de Janeiro, Rio de Janeiro, RJ, Brasil.

Contato: victoria.brantr@gmail.com 


\title{
The pedagogical formation in higher education and the role of stricto sensu graduate studies
}

Guilherme Torres Corrêa'

Victoria Maria Brant Ribeiro"

\begin{abstract}
This work was developed based on the idea that being a higher education teacher is not just a question of having command of contents, of having expertise in a given field. The pedagogical practice at that level is complex, contextualized, often unpredictable, and is shaped by ethical and political choices. In this sense, we understand that teaching demands a formative process that may have as its initial stage stricto sensu graduate studies. From such discussions we have established as our objective to study the way in which pedagogical formation is treated within higher education public policies, more specifically with respect to stricto sensu graduate studies. For that, we have made use of two methodological frameworks: Pierre Bourdieu's field theory and the critical discourse analysis by Norman Fairclough. Understanding graduate studies as a scientific field, and the analysis of the National Plan for Graduate studies, indicated that this level of higher education is basically focused on the accumulation of scientific capital and on the formation of scientific habitus, all amidst a silence about the teaching dimension of doing and being a teacher. We concluded that there is a need to develop a culture of valuing teaching at the University, a process that can have in the valuation of a pedagogical capital and in the formation of the pedagogical habitus in stricto sensu graduate studies a highly relevant stage.
\end{abstract}

\section{Keywords}

Pedagogical formation - Teacher education - Higher education teaching - Graduate studies. 
A atividade docente no ensino superior tem tido seu valor e seu significado considerados com maior frequência e consistência a partir do final do século XX, quando teve início um processo de autocrítica por parte de diferentes membros integrantes das universidades sobre essa prática (MASETTO, 2009). Apesar do despertar para o autoquestionamento, Isaia (2006) nos apresenta um quadro de ausência de compreensão por parte de professores e de instituições sobre a necessidade de preparação específica para exercer a docência. Segundo a autora, mesmo estando cientes de sua função formativa, os professores não consideram a necessidade dessa preparação e acreditam que o conhecimento específico desenvolvido nos anos de formação inicial ou ao longo da carreira, além do exercício profissional, é o bastante para assegurar o bom desempenho docente.

De acordo com Libâneo (2011), o professor deve ter, antes de tudo, a formação na matéria que leciona e, além disso - o que é o foco deste trabalho -, uma formação didático-pedagógica em que se estabeleça a ligação dos princípios gerais que regem as relações entre o ensino e a aprendizagem, com problemas específicos do ensino de determinada matéria. Para tanto, são necessários alguns conhecimentos e práticas, como:

- definir objetivos explícitos ou implícitos, de cunho ético, ideológico, filosófico e político, que direcionam o trabalho docente;

- transformar o saber científico em conteúdos formativos, tendo em vista os objetivos educativos;

- utilizar procedimentos de ensino para além dos recorrentes nos métodos de investigação da matéria ensinada;

- entender que é membro de um grupo em uma estrutura organizacional, em que são compartilhados valores, opiniões, crenças e práticas de interação e convivência;

- estabelecer determinados modos de interação social com os estudantes, com implicação de elementos afetivos.

Tais conhecimentos e práticas são relevantes na medida em que o ensino é uma atividade complexa, contextualizada, muitas vezes imprevisível e que demanda escolhas éticas e políticas, conforme apontam Pimenta e Anastasiou (2008). Para essas autoras, o conhecimento do docente tem como base a sensibilidade da experiência e a indagação teórica; ele emerge da prática (refletida) e se legitima em projetos de experimentação reflexiva e democrática do processo de (re)construção das práticas institucionais. Portanto, a formação de professores demanda investimentos acadêmicos para que os docentes possam estabelecer a relação com o campo e o contexto de produção dos conhecimentos na história e na sociedade; além disso, esse processo formativo deve estimular o professor a entender a prática educativa como forma de aprender. Nesse contexto, muito embora o educador e o educando sejam diferentes entre si, "quem forma se forma e re-forma ao formar e quem é formado forma-se e forma ao ser formado" (FREIRE, 1996, p. 23). Para Freire, não há docência sem discência; as duas se explicam e seus sujeitos, apesar das diferenças que possuem, não se reduzem à condição de objeto um do outro: quem ensina aprende ao ensinar e quem aprende ensina ao aprender.

Todavia, como não há formação específica para os processos de ensino e aprendizagem, o professor universitário desconhece cientificamente os elementos constitutivos da própria ação docente, tais como o planejamento, a organização da aula, as metodologias e estratégias didáticas, a avaliação e as peculiaridades da interação professor-aluno (ALMEIDA; PIMENTA, 2009). 0 quadro geral dos processos formativos de professores universitários nos programas de pós-graduação stricto sensu é caracterizado pela preparação, por meio do desenvolvimento de conhecimentos teóricos e instrumentai,s da atividade de pesquisa e de produção de conhecimento, com apropriações referentes ao campo científico de atuação (ALMEIDA; PIMENTA, 2009). Nesse contexto, Cunha et al. (2005) explicam que, apesar da existência de uma literatura contemporânea que procura redimensionar a 
profissionalidade docente no sentido da autonomia e da reflexão, a universidade segue um caminho inverso, em que prevalece o foco na formação de profissionais que se ajustam às demandas do mercado em detrimento de um processo educativo pautado pela construção da cidadania e da consciência crítica.

Em consonância com esse quadro, Soares e Cunha (2010) atentam para a falta de exigência nas políticas públicas de uma formação para o professor da educação superior que contemple os saberes específicos da prática docente. Referindo-se a diversos estudos, as autoras argumentam que o professor universitário constrói sua identidade docente a partir das vivências familiares, dos modelos de antigos professores e da própria experiência autodidata, além das trocas com colegas de profissão e do retorno dos estudantes. Elas ressaltam que ainda são poucos os trabalhos sobre a formação docente universitária em programas de pós-graduação stricto sensu, mas é possível afirmar que a formação nesse espaço é de grande relevância, apesar da evidente insuficiência de iniciativas, que deveriam contar com maior valorização institucional e dos órgãos de fomento e avaliação.

Ao assumirmos que os programas de pós-graduação stricto sensu se configuram como uma importante fase para a formação pedagógica do professor universitário, principalmente porque esse processo possibilita a qualificação da prática docente (CUNHA et al., 2005; ISAIA, 2006; PIMENTA; ANASTASIOU, 2008; MASETTO, 2009; SOARES; CUNHA, 2010), temos claro, assim, o objetivo de nosso trabalho: estudar de que modo essa formação é discutida no âmbito das políticas públicas para o ensino superior, mais especificamente no que tange à pós-graduação.

0 primeiro passo para alcançarmos esse objetivo foi entender como se estrutura e funciona a pós-graduação stricto sensu no Brasil. Buscamos compreendê-la à luz da teoria dos campos do sociólogo francês Pierre Bourdieu, fundamentalmente porque essa teoria entende por campo um espaço social de relativa autonomia em relação ao espaço social global, o que é o caso da pós-graduação.

\section{A teoria dos campos}

Bourdieu (2010), de modo mais amplo, dispõe-se a elaborar uma teoria do espaço social, compreendendo-o como um espaço objetivo multidimensional baseado em princípios de diferenciação ou de distribuição. Tais princípios, segundo ele, são constituídos pelo conjunto das propriedades que aí atuam, as quais conferem força ou poder aos seus detentores, sendo que os agentes e grupos de agentes são definidos por suas posições relativas nesse espaço. Tais propriedades atuantes são as diferentes espécies de capital presentes nos diversos campos, e os agentes se distribuem no espaço social em duas dimensões, de acordo com o capital: na primeira dimensão, segundo o volume global de capital que possuem; na segunda, segundo a composição (estrutura) de seu capital, conforme o peso relativo das diferentes espécies no conjunto de suas posses. 0 capital funciona como uma moeda própria (não necessariamente no sentido econômico), como um recurso útil na determinação e na reprodução das posições sociais de um campo específico do espaço social global, e sua posse é a condição para que os agentes participem do jogo social e que nele possam, em virtude de suas jogadas, acumular mais capital (BRANDÃO, 2010; THIRY-CHERQUES, 2006). Nesse sentido, denomina-se capital específico aquele que vale em relação a determinado campo, dentro dos limites desse campo, e que só é convertível em outra espécie de capital sob certas condições (BOURDIEU, 2003).

Para Bourdieu (2004), o espaço social é configurado por diferentes campos. 0 campo é um espaço relativamente autônomo, um microcosmo dotado de suas leis próprias. Esse microcosmo não escapa às leis sociais do espaço social global, mas possui em relação a este uma autonomia parcial mais ou menos acentuada. Um campo é definido, entre outros aspectos, por 
meio da definição dos objetos de disputa e dos interesses específıcos nesse espaço. E, para que funcione, é necessário que haja objetos de disputa e indivíduos prontos a disputarem o jogo, dotados de habitus que impliquem o conhecimento e o reconhecimento das leis imanentes ao jogo, dos objetos de disputa etc. (BOURDIEU, 2003).

0 habitus é uma espécie de senso prático, um sistema adquirido (incorporado) de preferências, de princípios de visão e de divisão, de estruturas cognitivas duradouras, que permite estabelecer uma relação inteligível e necessária entre determinadas práticas e uma situação, cujo sentido é produzido por ele em função das categorias de percepção e apreciação (BOURDIEU, 2005, 2008). O habitus é o princípio unificador e gerador de práticas que retraduzem as características intrínsecas e relacionais de uma posição em um estilo de vida próprio, em um conjunto unívoco de escolhas (BOURDIEU, 2005). 0 fato de as categorias de percepção do mundo social serem o produto da incorporação das estruturas objetivas do espaço social leva os agentes a tomarem o mundo social como natural, o que dificulta a possibilidade de se revoltarem contra ele (BOURDIEU, 2010). Aqueles que adquirem, em um campo diferente do que estão inscritos, as disposições que não são as que este exige, correm o risco de se apresentarem deslocados. Mas há a possibilidade de resistência: os agentes podem, em vez de submeterem seus habitus às estruturas, lutar com as forças do campo, tentar transformar as estruturas a fim de conformá-las às suas disposições (BOURDIEU, 2004).

A partir desses elementos teóricos, podemos compreender a pós-graduação stricto sensu como campo e analisar a questão da formação pedagógica.

\section{Pós-graduação stricto sensu: o campo científico}

A pós-graduação stricto sensu é caracterizada pelo mestrado acadêmico e profissional e pelo doutorado acadêmico. Nosso enfoque será sobre o mestrado e o doutorado acadêmicos, em que se apresenta mais claramente a formação pós-graduada com intenção de carreira acadêmica e, consequentemente, a possibilidade de atuação como professor universitário.

Martins (2002) descreve alguns fatores fundamentais para a configuração e a consolidação da pós-graduação nacional. Entre eles, estão: os pareceres 977/65 e 77/69 do extinto Conselho Federal de Educação, que tiveram importância na defınição conceitual e na moldura legal da pós-graduação; os planos nacionais de pós-graduação, imprimindo uma direção para a consolidação e a institucionalização da pós-graduação por meio de diagnósticos e da formulação de metas e ações; e o processo de avaliação e fomento à pesquisa como um todo, principalmente na figura da Capes (Coordenação de Aperfeiçoamento de Pessoal de Nível Superior) e do CNPq (Conselho Nacional de Desenvolvimento Científico e Tecnológico). A pós-graduação stricto sensu é indispensável para a formação e a qualificação dos quadros de pessoal do ensino superior, e tem-se constituído como o principal instrumento de modernização desse nível de educação (MARTINS, 2002; BRASIL, 2004).

A pós-graduação stricto sensu é avaliada e classificada, basicamente, por duas perspectivas, cada uma correspondente a um órgão específıco: de um lado, a Capes conduz acompanhamentos anuais e avaliações trienais de desempenho de todos os programas que integram o Sistema Nacional de Pós-Graduação, em uma abordagem que está orientada para a qualidade dos programas como um todo e que influencia o financiamento de tais programas; de outro, há a avaliação do CNPq, cujo enfoque está nos pesquisadores e nos líderes de grupos de pesquisa, a partir de critérios de produtividade acadêmica, relevância e mérito de proposta de pesquisa, dedicação ao projeto, entre outros, o que também influencia o financiamento.

Tanto as instituições quanto os agentes pertencentes à pós-graduação participam e ajudam a desenvolver o jogo que aí se produz, 
sendo que, de modo geral, os objetivos e as regras do campo são explícitos. Bourdieu (1983, 2004) denomina a pós-graduação como campo científico, expressão que utilizaremos neste trabalho. Podemos enunciar os objetivos e as regras de acordo com os principais agentes (e suas relações) do campo, entre eles: burocratas, professores-pesquisadores, alunos (pós-graduandos) e funcionários de apoio técnico-administrativo. Daremos destaque para os dois primeiros; os alunos aparecerão durante a discussão.

0 campo científico comporta duas formas de poder correspondentes a duas espécies de capital científico. Uma delas é o poder político, relativo à acumulação de capital científico institucionalizado e ligado à ocupação de posições importantes nas instituições científicas e políticas - como comissões, representações etc. - relativas a órgãos colegiados, reguladores, avaliadores, financiadores e gestores, entre outros. 0 capital científico institucionalizado é acumulado por estratégias políticas específicas que exigem tempo, como a participação em comissões, bancas de teses e concursos, reuniões e outros eventos mais ou menos convencionais no plano científico, sendo que muitas vezes não é possível saber se a acumulação desse tipo de capital é o princípio (a título de compensação) ou o resultado de um menor êxito na acumulação do capital científico puro, o qual está mais relacionado aos burocratas. Tal capital científico puro é a espécie que corresponde à outra forma de poder, mais específico, que é o prestígio pessoal, o reconhecimento científico propriamente dito, adquirido fundamentalmente pelas contribuições reconhecidas ao progresso da ciência, e que diz respeito, principalmente, aos professores-pesquisadores (BOURDIEU, 2004).

Nesse sentido, os burocratas são os agentes que ocupam as posições referentes ao poder político, em que se pode acumular o capital científico institucionalizado. Essas posições distribuem-se em diversos órgãos do campo, com diferentes funções (legislativas, administrativas, avaliativas, reguladoras, financiadoras etc.), das quais cabe destacar algumas: as diversas instâncias do MEC, as chefias de departamento, as reitorias, a Capes e o CNPq. 0 acesso a tais posições, pelo menos às de maior poder, dá-se, principalmente, por meio de eleições internas e indicações de membros pares ou até mesmo do Presidente da República.

Já os professores-pesquisadores acessam o campo, basicamente, por contratação direta ou concurso público. 0 acesso e o deslocamento no campo dependem do capital cultural e, sobretudo, científico acumulado, obtido pela experiência, pela produção acadêmica, por títulos, publicações de artigos científicos em periódicos pertinentes à área, participação em congressos, orientações de pós-graduandos etc. Uma vez que o capital científico é o tipo mais valorizado e reconhecido no campo, sendo fundamentalmente produto de pesquisa, as atividades de ensino ficam em segundo plano, pelo menos no que tange à preocupação com sua qualidade e reflexão sobre a prática. Destarte, não é absurdo falar em um senso prático do jogo voltado para a pesquisa, um habitus menos de professor do que de pesquisador (BOURDIEU, 1983, 2004; FERNANDES, 2001; ISAIA, 2006; MASETTO, 2009; SOARES; CUNHA, 2010).

As práticas no campo científico estão voltadas principalmente para a aquisição de prestígio e reconhecimento (autoridade científica). A busca do reconhecimento nada mais é do que a acumulação de capital científico puro, que de fato é a espécie de capital científico dominante no campo, incorporado mais clara e objetivamente nos sistemas de avaliação e classificação dos programas de pós-graduação e como habitus nos pesquisadores. Também está em jogo, porém, a outra espécie de capital científıco, o institucionalizado, que permite ocupar posições em que são discutidos e construídos os critérios concretos de avaliação e classificação que influenciam o processo de aquisição e reconhecimento do capital científico puro (BOURDIEU, 1983, 2004).

No campo científico, o pesquisador objetiva realizar as pesquisas que ele considera importantes, mas isso não basta; ele também 
precisa trabalhar com o interesse dos outros, com os problemas dos outros pesquisadores, pois isso é o que lhe permite obter um lucro simbólico, o reconhecimento de fato (BOURDIEU, 1983). É nesse contexto que se evidencia a questão orientadora de nosso trabalho, já que a formação pedagógica não parece constituir-se como um objeto de interesse para o campo científico, não se apresenta como um capital relevante aos agentes, ou mesmo como um habitus (pois que é geradora de práticas) que se ajustaria ao campo, permitindo aos agentes alcançarem posições importantes. 0 capital adquirido e o habitus incorporado por meio do processo de formação pedagógica, os quais podemos chamar de capital e habitus pedagógicos, não conferem possibilidades concretas de reconhecimento no campo aos agentes. Destarte, cabe perguntar: como torná-los objeto de interesse e reconhecimento no campo científico?

A distribuição desigual de capital científico no campo configura uma luta desigual entre os agentes. Os dominantes, normalmente pesquisadores mais experientes, ocupam as posições mais importantes na estrutura de distribuição do capital e caracterizam-se por terem estratégias de conservação dessa estrutura, com o objetivo de assegurar a perpetuação da ordem científica estabelecida com a qual estão de acordo. Já os dominados, comumente os novatos, pós-graduandos ou recém-chegados, ou ainda os professores-pesquisadores mais experientes que não estão completamente de acordo com o jogo jogado, podem orientar-se por estratégias de sucessão, que lhes possibilitam mais concretamente assegurar os lucros prometidos aos que realizam o ideal científico do campo, ou por estratégias de subversão, que se caracterizam por investimentos muito custosos e arriscados, e que garantem legitimidade somente pela redefinição dos problemas relevantes para o campo (BOURDIEU, 1983). Mais especificamente sobre os recém-chegados, Bourdieu (2004, p. 30) afirma que eles são implicados em uma forma particular de illusio inerente ao pertencimento a um campo, que nada mais é do que uma crença científica como interesse desinteressado e interesse pelo desinteresse, o que os leva a admitir

que o jogo científico merece ser jogado, que ele vale a pena, e que define os objetos dignos de interesse, interessantes, capazes, portanto, de merecer o investimento.

Nesse sentido, cabe voltar à pergunta feita anteriormente: como redefinir os problemas relevantes para o campo de modo que a formação pedagógica se torne um objeto de interesse e seja merecedora de investimento pelos agentes?

Há outros elementos que compõem e determinam a estrutura do campo científico, como os periódicos científicos, mas, devido ao limite de espaço, abordaremos o sistema de ensino. Este assegura a reprodução e a circulação dos produtores (ou reprodutores) e consumidores dos bens científicos produzidos, além de garantir à ciência oficial a permanência e a consagração, ao inculcar sistematicamente habitus científicos àqueles destinatários legítimos da ação pedagógica, principalmente aos pós-graduandos (BOURDIEU, 1983). Se é na pós-graduação que esse habitus científico começa a ser mais consistentemente inculcado aos agentes (alunos: os pós-graduandos), não seria esse um momento importante de contrabalanceamento com a incorporação de um habitus pedagógico?

$\mathrm{Na}$ medida em que estabelecemos como objetivo o estudo do modo em que se dá a discussão da formação pedagógica no âmbito das políticas públicas para o ensino superior, em especial para a pós-graduação (agora compreendida como um campo), elencamos como material de análise a política pública mais importante para esse campo: o Plano Nacional de Pós-Graduação (PNPG). Neste trabalho, analisamos o IV Plano Nacional de Pós-Graduação (2005-2010), que anunciava entre os objetivos para a pós-graduação no período de sua vigência: 
o fortalecimento das bases científica, tecnológica e de inovação; a formação de docentes para todos os niveis de ensino; a formação de quadros para mercados não acadêmicos. (BRASIL, 2004, p. 58-59, grifo nosso)

Vale destacar que está em vigência o $\mathrm{V}$ PNPG (2011-2020), mas ainda não tivemos a oportunidade de analisá-lo, pois não havia sido publicado quando do início da pesquisa que deu origem a este artigo. Todavia, uma leitura transversal do documento parece-nos indicar que os achados não seriam muito diferentes dos discutidos aqui a respeito do IV PNPG. Cabe, em outro momento, tomá-lo como objeto de análise mais concreta.

Para desenvolvermos o estudo do PNPG, tomamos como referência, além da teoria dos campos de Bourdieu, a análise crítica do discurso (ACD) de Norman Fairclough, linguista inglês. Optamos por esse percurso metodológico por dois motivos: em primeiro lugar, como o PNPG é um material eminentemente discursivo, sentimos necessidade de adotar um referencial analítico com enfoque no discurso; em segundo lugar e complementarmente, o próprio Fairclough incorpora em seu método elementos da teoria dos campos de Bourdieu, só não o faz de modo sistemático, tarefa que tentamos concretizar neste trabalho.

\section{Análise crítica do discurso}

0 referencial da análise crítica do discurso (ACD) situa-se dentro do contexto de uma pesquisa crítica sobre as mudanças econômicas, sociais e culturais na sociedade contemporânea. Chouliaraki e Fairclough (1999) afırmam que parte significativa das transformações na sociedade contemporânea são transformações no discurso; além disso, várias das transformações que se desenvolvem fora dos discursos também são moldadas por eles. Todavia, os autores lembram que, apesar da importância social do discurso, não é possível reduzir a vida social a ele, e por isso a ACD trabalha com uma visão dialética entre os elementos discursivos e não discursivos do mundo social.

Chouliaraki e Fairclough (1999) utilizam o termo discurso em referência aos elementos semióticos das práticas sociais, o que inclui a linguagem (falada e escrita, e suas combinações), a comunicação não verbal (gestos, expressões faciais etc.) e imagens visuais (fotografias, filmes). A vida social em si é feita de práticas, que são entendidas como "modos habituais, ligados a tempos e lugares particulares, em que as pessoas aplicam recursos (materiais ou simbólicos) para agirem juntas no mundo" (CHOULIARAKI; FAIRCLOUGH, 1999, p. 21). Em determinada prática, os diversos elementos da vida são reunidos no que os autores chamam de momentos da prática, sendo cada momento visto como internalizando os outros sem se reduzir a eles. Os autores descrevem quatro momentos principais adaptados de Harvey (apud CHOULIARAKI; FAIRCLOUGH, 1999): atividade material, relações e processos sociais, fenômenos mentais e discurso.

Para Fairclough (2009), há três grandes formas em que o discurso se relaciona a outros elementos das práticas e dos eventos sociais: como uma faceta da ação; na construção (ou representação) de aspectos do mundo; e na constituição de identidades. Nesse sentido, Fairclough $(2003,2009)$ apresenta três categorias analíticas semióticas que correspondem a essas formas: gênero, discurso e estilo. A fim de facilitar a compreensão, as três categorias são explicadas mais adiante, ao longo da análise.

Cabe ainda mencionar duas categorias: a intertextualidade, ou seja, a presença em um texto (dimensão semiótica de um evento) de elementos de outros textos que podem ser relatados de modos diversos, explicitamente demarcados ou não; e a interdiscursividade, que pode ser considerada parte da intertextualidade de um texto, referindo-se aos gêneros, discursos e estilos em que ele se baseia, e ao modo como esses diferentes gêneros, discursos e estilos são articulados (CHOULIARAKI; FAIRCLOUGH 1999; FAIRCLOUGH, 2003, 2009). 
Conforme já apontamos, Fairclough procura incorporar elementos da teoria de Bourdieu ao seu referencial. Para o linguista inglês, a dimensão semiótica das práticas sociais - que constituem campos, instituições e organizações sociais - são as ordens de discurso. Uma ordem de discurso é uma articulação socialmente estruturada das práticas que constituem a faceta discursiva de um espaço social, ou seja, é a lógica organizacional discursiva de um campo. Assim, a análise da ordem de discurso pode ser vista como parte da análise social de um campo (CHOULIARAKI; FAIRCLOUGH, 1999; FAIRCLOUGH, 2009).

É o caso do campo científico (pós-graduação stricto sensu), configurado por uma rede de práticas sociais - tais como a formulação de políticas e diretrizes, a avaliação, o fomento à pesquisa, a pesquisa científica e a divulgação científica - que possuem uma dimensão discursiva. Dentre essas práticas, tal como já destacamos, nosso interesse principal reside na formulação de políticas e diretrizes. Martins (2002) salienta que essa prática tem (e teve) um papel fundamental na consolidação, na institucionalização e no status da pós-graduação stricto sensu nacional, principalmente porque ela serve (e serviu) de estímulo ao desenvolvimento das outras práticas sociais que compõem e estruturam o campo científico.

A formulação de políticas e diretrizes no campo científico tem como um de seus eventos concretos o Plano Nacional de PósGraduação (PNPG), de relevância inquestionável. Fairclough (2009) afirma que a dimensão discursiva de um evento é seu texto, e o PNPG é fundamentalmente (não exclusivamente) discursivo (textual). Tal como dito anteriormente, foi ele o material empírico que selecionamos para nosso estudo.

\section{Análise textual}

O Plano Nacional de Pós-Graduação (PNPG) é um dos principais, senão o principal, documento de formulação para o campo científico no Brasil. Ao lado do Plano Nacional de Educação (PNE), ele deve exercer um papel fundamental nos rumos da pós-graduação, estimulando a integração entre o sistema universitário nacional e as políticas de desenvolvimento socioeconômico e científico-tecnológico do país. Além disso, sua elaboração e sua implementação devem ser consequências de uma política de Estado para o ensino e a pesquisa no Brasil, evitando, assim, que decisões vulneráveis aconteçam segundo o jogo das circunstâncias (ANPEd, 2004). Ao longo do tempo, foram elaborados e postos em prática quatro planos desse nível: o I PNPG (19751979), o II (1982-1985), o III (1986-1989) e o IV (2005-2010). Atualmente, estamos em um período entre planos, já que o IV PNPG teve seu prazo esgotado em 2010 e foi publicado recentemente o V PNPG (2011-2020). É sobre o IV PNPG que discutiremos a seguir.

O IV PNPG foi elaborado por uma comissão de dez membros, os quais representavam: a Capes, o CNPq, a comunidade acadêmica, o Fórum Nacional de Pró-Reitores de Pesquisa e PósGraduação das Instituições Brasileiras (FOPROP), a Associação Nacional de Pós-Graduandos (ANPG) e a Financiadora de Estudos e Projetos (FINEP). Fica evidente que a responsabilidade de elaboração do documento foi de agentes possuidores de capital científico institucionalizado.

A análise textual inclui tanto uma análise linguística quanto uma análise interdiscursiva, sendo que esta última compara o modo como gêneros, discursos e estilos são articulados em um texto como parte de um evento específico. Para o objetivo deste trabalho, focalizamos a análise interdiscursiva, que, para Fairclough (2003), é o nível intermediário em que são analisados os gêneros, os discursos e os estilos; tal nível é de cunho intermediário porque faz a mediação entre o texto e o contexto social. Como o espaço de um artigo é limitado, não fizemos uma análise exaustiva do IV PNPG como um todo, que pode ser consultada em outro trabalho (CORRÊA, 2012). Aqui usamos a categoria gênero para caracterizar de forma mais ampla o documento, e 
as categorias discurso e estilo para analisar a discussão sobre formação pedagógica, que é o foco de nosso estudo.

Fairclough (2003, 2009) descreve os gêneros como modos discursivos de agir e interagir no curso dos eventos sociais; quando analisamos um texto em termos de gênero, perguntamos como ele se apresenta e contribui para a ação e a interação social nesses eventos. Referir-se ao gênero é referir-se às formas de ação e interação, à estrutura do aspecto discursivo de práticas como uma entrevista de trabalho ou um artigo científico. Determinada prática social não implica necessariamente determinado gênero; no curso dos eventos, os agentes podem utilizar diferentes tipos de gênero, mas, de algum modo, há forte relação entre prática e gênero (FAIRCLOUGH, 2003). Existe a possibilidade de um texto não ser produzido segundo um único gênero, podendo hibridizar dois ou mais gêneros (FAIRCLOUGH, 2003), tal como o documento que estamos analisando. Nesse sentido, a estrutura híbrida não é sua exclusividade, mas pode ser encontrada inclusive em outros planos oficiais.

No IV PNPG, tem-se, primeiramente, uma seção introdutória em que se discorre sobre dois pontos: a importância do tema a que se propõe debater o plano (a pós-graduação stricto sensu brasileira); e o histórico do que se está discutindo, principalmente por meio da discussão dos PNPG anteriores e do processo de elaboração do IV. Ao longo da seção, recorre-se frequentemente a referências a outros textos, os quais, em sua maioria, são documentos oficiais, como leis, decretos ou demais planos. Apenas a título de identificação, denominamos esse gênero histórico oficial. É evidente o uso da intertextualidade como um recurso de construção do documento, funcionando, nesse caso, como uma estratégia de legitimação por autorização (VAN LEEUWEN apud FAIRCLOUGH, 2003), uma vez que os produtores do texto se referem a alguma autoridade - os textos oficiais - para alcançar legitimidade sobre o tema em pauta. Além disso, já dissemos que os produtores do texto possuem quantidade importante de capital científico institucionalizado, o que garante uma legitimidade ainda maior ao documento.

A segunda seção do plano consiste no diagnóstico e na análise do campo relacionado ao tema em discussão. Podemos afirmar que essa segunda seção caracteriza-se como um gênero de avaliação de políticas, sendo também atravessada pela intertextualidade e permeada por gráficos, tabelas, dados estatísticos e demais elementos oriundos de outros textos (em grande parte, de órgãos estatais ou pesquisadores renomados). Esse tipo de informação gráfica e numérica produz um caráter de objetividade e neutralidade; portanto, além de se tratar de uma estratégia de legitimação por autorização, também é uma estratégia de legitimação por racionalização (VAN LEEUWEN apud FAIRCLOUGH, 2003) que conforma um processo de legitimação pela quantidade de capital científico puro incorporado na seção.

A última seção mais claramente delimitada do plano se caracteriza pela proposição de diretrizes, objetivos e metas, o que podemos chamar de gênero político-gerencial. Essa parte do texto apresenta uma intertextualidade muito mais interna do que externa, uma vez que se refere frequentemente ao diagnóstico e à avaliação da seção anterior para elaborar as diretrizes como um todo, acabando por funcionar como um terceiro momento de legitimação da seção anterior, pois toma o que foi dito como referência, verdade, como informação essencial para seu desenvolvimento.

Os discursos são modos de representar aspectos do mundo. Aspectos particulares do mundo podem ser representados de maneira diversa, e os vários discursos são diferentes perspectivas sobre o mundo, estando suas relações atreladas às relações entre as pessoas. Apresentamos, a seguir, quatro passagens que selecionamos do documento; nas duas primeiras, indicamos em itálico os trechos que mais nos interessam aqui. 
Apesar do expressivo aumento no número de cursos e de egressos na pós-graduação, constata-se ainda a necessidade da formação de quadros docentes para atuar nos diferentes niveis de ensino, conforme comentado no item anterior. (BRASIL, 2004, p. 27, grifo nosso)

0 diagnóstico apresentado ao longo desse documento indica que a expansão do sistema deve ter quatro vertentes: a capacitação do corpo docente para as instituições de Ensino Superior, a qualificação dos professores da educação básica, a especialização de profissionais para o mercado de trabalho público e privado e a formação de técnicos e pesquisadores para empresas públicas e privadas. (BRASIL, 2004, p. 48, grifo nosso)

A necessidade de qualificação para os professores do ensino fundamental, médio e técnico exige uma reflexão sobre qual seria o melhor caminho a ser seguido para atender a essa demanda. Vislumbra-se a possibilidade de estimular a criação de programas de mestrado voltados para a formação de professores em serviço, em articulação e cooperação com os sistemas de ensino. (BRASIL, 2004, p. 48)

Considerando a qualificação deficitária do corpo docente da educação básica, principalmente na etapa do ensino fundamental, é necessário que os programas de pós-graduação se envolvam na pesquisa educacional para encontrar os melhores métodos e técnicas de educação à distância que possibilitem a formação qualificada do universo docente em atividade, aproveitando-se das iniciativas exitosas existentes no país. (BRASIL, 2004, p. 60)

No texto há diversas passagens que tratam da formação, da capacitação ou da qualificação docente. A observação mais relevante que podemos fazer é que em nenhum lugar do texto é explicado claramente o que se entende por esse processo, independentemente da denominação - formação, qualificação ou capacitação. Tais passagens são voltadas ora para o ensino superior, ora para a educação básica, ora para ambos os níveis. A partir dos quatro excertos transcritos, observamos que nos dois últimos há uma tentativa de se pensar em modelos de qualificação de professores. Entretanto, essa questão é estritamente referente aos docentes da educação básica. Segundo o texto, a necessidade de qualificação desses professores exige uma reflexão sobre o melhor caminho para tal. Mas e quanto à necessidade de capacitação dos professores do ensino superior? Nada se exige a esse respeito? Basta a titulação acadêmica em um programa de pós-graduação de qualidade? Enfim, impera o silêncio sobre a formação pedagógica para o ensino superior, o que nos leva a concluir que há uma pressuposição, discursivamente construída, de que um pesquisador muito bem formado (titulado, pós-graduado) consequentemente será (é) um professor muito bem qualificado.

Para fecharmos a análise interdiscursiva, resta discutir a categoria estilo. Fairclough (2003) explica que os estilos são aspectos discursivos dos modos de ser, estando ligados à identificação: quem é você é, em parte, uma questão de como você fala ou escreve. Trabalharemos o estilo com foco em seus dois aspectos principais de análise, que são a modalidade e a avaliação. Fairclough (2003) descreve que a modalidade se refere a como as pessoas se comprometem com o que dizem; ela é vista em termos das relações dos falantes ou escritores - do autor - com os discursos. Neves (2011) apresenta quatro tipos de modalidade que variam de acordo com o elemento (verbo, substantivo, advérbio ou adjetivo): a epistêmica indica uma crença, uma opinião, uma expectativa sobre uma asserção e está ligada ao conhecimento; a delimitadora determina o ponto de vista sob o qual uma asserção pode ser considerada verdadeira; a deôntica exprime consideração de necessidade por obrigatoriedade e está ligada ao dever; e a 
afetiva indica um estado de espírito em relação ao conteúdo da asserção. Já a análise pelo aspecto da avaliação se dá pela compreensão dos modos, explícitos ou implícitos, por meio dos quais o autor se compromete com valores em termos do que é desejável ou indesejável.

Embora tenhamos transcrito aqui algumas passagens em que a questão da docência é discutida, a análise de estilo a seguir pode ser estendida para o documento como um todo. Sublinhamos os elementos de modalidade e destacamos em itálico os elementos de avaliação:

Por outro lado, deve-se assinalar que, no ano de 2003, dos 254.153 docentes que atuavam nesse nível de ensino (superior), somente 54.487 (21,5\%) possuíam o doutorado e $89.228(35,1 \%)$ apenas o mestrado. (BRASIL, 2004, p. 25, grifo nosso)

Os dados apresentados da Tabela 2 evidenciam a necessidade de se investir fortemente na titulação dos docentes que atuam nas IES, tendo como parâmetro a melhoria do ensino em sua fase atual e a necessidade de sua expansão qualificada. (BRASIL, 2004, p. 26, grifo nosso)

Os dados apresentados demonstram que a necessidade de capacitação de docentes, tanto para a educação básica quanto para a superior, continua sendo uma das tarefas centrais da pós-graduação brasileira. (BRASIL, 2004, p. 26, grifo nosso)

Essas passagens contêm a assunção de que a titulação dos docentes é fator inerente de qualificação, capacitação ou formação. A partir delas se pode perceber que (o que é característica do documento como um todo, e não apenas das passagens sobre docência) o texto é trabalhado com alto grau de comprometimento epistêmico e deôntico e de avaliação desejável (positiva), o que configura uma posição de concordância plena em relação aos temas, às informações e aos diagnósticos expostos, bem como uma posição de necessidade indubitável dos diversos objetivos, das diretrizes e das metas apresentadas. No que tange à docência, essas passagens demonstram um comprometimento com a ideia de qualificação pela titulação. 0 que temos, na verdade, é um discurso circular, pois, ao não explicitar em nenhum momento o que se entende sobre a profissão docente, o documento leva à compreensão de que a pós-graduação é uma fase fundamental na qualifıcação docente e de que o docente qualificado é aquele possuidor de título. Considerando-se o silêncio sobre o que claramente se entende em relação ao fazer docente, o capital científico incorporado, em suas diferentes espécies, e os recursos textuais já apontados, que reforçam esse capital e estabelecem a legitimidade do plano no campo, pode-se dizer que o documento apresenta um perfil de professor qualificado/capacitado pelo que é como pesquisador.

\section{Estudando o campo, analisando os discursos}

As conclusões que retiramos da análise podem ser assim resumidas: no que tange à pós-graduação stricto sensu, há estratégias e discursos muito claros de valorização do capital científico e de busca da formação de um habitus científico nos agentes do campo; por outro lado, há quase que uma negligência (discursiva e estratégica) de questões que apontam a relevância/necessidade da existência de formação pedagógica nesse espaço. Destarte, perguntamo-nos: qual é a relação dos discursos analisados com a estrutura do campo estudado?

Entendemos que o campo científico poderia funcionar da mesma maneira se as políticas públicas (PNPG), a progressão na carreira docente e as avaliações das instituições universitárias, entre outros elementos, valorizassem as atividades de formação e produção pedagógica. 0 ocultamento do discurso pedagógico nos textos estruturantes do campo científico não necessariamente é essencial para a lógica de funcionamento do campo, mas apenas parece concentrar e reforçar o interesse dos agentes em um tipo de 
objeto: o científico. Nesse sentido, a emergência do objeto pedagógico como alvo de interesse para os agentes apenas poderia fazer com que esse tipo de objeto tivesse maior relevância no campo. Todavia, será que a valorização do capital pedagógico - tal como o científico é valorizado - e a formação de um habitus pedagógico - tal como o habitus científico é formado (na lógica da produtividade) - são objetivos almejados por aqueles que lutam pela formação pedagógica na universidade?

A resposta parece óbvia diante do que expusemos e da posição que assumimos: não. Mas, dentro da estrutura dos campos estudados e do tempo em que se desenvolve a pós-graduação, é possível formar pedagogicamente? Sim, principalmente porque, assim como a formação do habitus científıco, a formação do habitus pedagógico é contínua, permanente. Não se trata de, em um período médio de dois ou quatro anos (mestrado/doutorado), formar integralmente um professor, mas de, nesse período, apresentar, discutir, refletir e construir elementos que subsidiam - e subsidiarão - uma prática social complexa: a docência no ensino superior. Trata-se de um início formal da construção de uma identidade docente.

A Capes exige de seus bolsistas de pós-graduação o estágio de docência. Mas observemos o artigo e alguns de seus critérios presentes no regulamento de concessão de bolsas:

Art. 18. 0 estágio de docência é parte integrante da formação do pós-graduando, objetivando a preparação para a docência, e a qualificação do ensino de graduação sendo obrigatório para todos os bolsistas do Programa de Demanda Social, obedecendo aos seguintes critérios:

I - para o programa que possuir os dois níveis, mestrado e doutorado, a obrigatoriedade ficará restrita ao doutorado;

II - para o programa que possuir apenas o nível de mestrado, a obrigatoriedade do estágio docência será transferida para o mestrado; V - a duração mínima do estágio de docência será de um semestre para o mestrado e dois semestres para o doutorado e a duração máxima para o mestrado será de dois semestres e três semestres para o doutorado; VII - o docente de ensino superior, que comprovar tais atividades, ficará dispensado do estágio de docência;

$\mathrm{X}$ - a carga horária máxima do estágio docência será de 4 horas semanais. (CAPES, 2010)

Como se observa, a Capes considera o estágio de docência parte integrante da formação do pós-graduando, mas já em seu primeiro critério determina que, em caso de haver no programa tanto mestrado quanto doutorado, a obrigatoriedade do estágio restringe-se ao último. Em outras palavras, entende-se que o mestrando continuará seus estudos na mesma instituição, como bolsista da Capes, e não poderá atuar como professor ao obter seu título de mestre; o segundo critério parece tentar amenizar essa contradição. Já no quinto critério, o texto estabelece uma duração mínima e máxima para o estágio. Mas com que argumento? E a carga horária? Bem, a carga horária máxima semanal é definida: 4 horas. Mas e a carga mínima? Encontramos em uma pesquisa mais ampla disciplinas de formação pedagógica com carga horária total de 15 horas (CORRÊA, 2012). Esse período forma alguém pedagogicamente? No sétimo critério, cabe apontar, ao dispensar do estágio de docência o pós-graduando que já atua como docente de ensino superior, o documento parece sugerir que o estágio de docência é apenas um momento de ministrar aulas, e não um processo formativo de reflexão sobre a própria prática pedagógica. Além disso, a Capes, que historicamente se constituiu ligada ao ensino superior, tem mais ações voltadas - e bem estruturadas - para a questão da docência na educação básica do que para a universidade, como é o caso do Programa Institucional de Bolsas de Iniciação à Docência (Pibid).

Nesse sentido, Cunha (2010) explica que a falta de legislação pertinente é uma das causas de as instituições não legitimarem os saberes pedagógicos necessários para o futuro 
docente. Há necessidade de transformação das universidades em territórios que

são percebidos por indicadores de legitimação incluindo o aporte legal que sustenta os programas de formação, pelo tempo de ocupação, que revela a intensidade de sua institucionalização e o reconhecimento de seus efeitos pelos beneficiários das ações formativas. (CUNHA, 2010, p. 121)

Portanto, é preciso que órgãos como a Capes se envolvam na construção, junto às universidades, de um ordenamento legal que incentive mais clara e estruturadamente a formação pedagógica no ensino superior. Mais do que isso, cabe às universidades, principalmente, a criação de ações permanentes de formação pedagógica, seja no âmbito da universidade como um todo, seja incentivando os programas de pós-graduação e as próprias graduações, ou mesmo valorizando e ampliando as experiências de sucesso, como grupos de apoio pedagógico (ANASTASIOU, 2009).

A formação pedagógica não necessita ser obrigatória, mas induzida e incentivada nos critérios de avaliação dos programas de pós-graduação e nas diretrizes específicas das políticas para o ensino superior. Enfim, entendemos que deve ser construída, coletivamente, uma cultura (um discurso) de valorização da docência na universidade, de modo que o ensino não seja visto como um fardo, mas, ao contrário, como um dos pilares da universidade, uma de suas razões de ser.

Há alguns limites neste trabalho, mas imaginamos que eles não são comprometedores do estudo. Poderíamos, por exemplo, ter analisado outros documentos oficiais de avaliação e regulação do campo a fim de compreender como o discurso do PNPG é recontextualizado e como a questão da formação pedagógica é abordada nesse âmbito, questões estas que poderão ser retomadas em outro momento

Concluindo, julgamos que a formação pedagógica não é a solução para todos os problemas do ensino superior, mas certamente é um processo que colabora nesse debate, ajudando a desestabilizar a estrutura do campo e possibilitando pequenas revoluções nos microcosmos das salas de aula das universidades brasileiras. 


\section{Referências}

ALMEIDA, Maria Isabel de; PIMENTA, Selma Garrido. Pedagogia universitária: valorizando o ensino e a docência na Universidade de São Paulo. In: ALMEIDA, Maria Isabel de; PIMENTA, Selma Garrido (Orgs.). Pedagogia universitária. São Paulo: EDUSP, 2009. p. 13-38.

ANASTASIOU, Léa das Graças Camargos. A teoria e a prática de processos de formaç̧ão continuada do docente universitário. In: ALMEIDA, Maria Isabel de; PIMENTA, Selma Garrido (Orgs.). Pedagogia universitária. São Paulo: EDUSP, 2009. p. 39-70.

ANPEd. V Plano Nacional de Pós-Graduação: subsídios apresentados pela ANPEd. Revista Brasileira de Educação, Rio de Janeiro, n. 27, p. 198-202, set./dez. 2004.

BOURDIEU, Pierre. A economia das trocas lingüísticas. In: ORTIZ, Renato (Org.). Bourdieu: Sociologia. São Paulo: Ática, 1983. p. 156-83. 2003. p. 119-26.

Algumas propriedades dos campos. In: Questões de sociologia. Lisboa: Edições Sociedade Unipessoal,

Os usos sociais da ciência: por uma sociologia clínica do campo científico. São Paulo: Editora UNESP, 2004.

Razões práticas: sobre a teoria da ação. 7. ed. Campinas: Papirus, 2005.

A distinção: crítica social do julgamento. São Paulo: EDUSP; Porto Alegre: Zouk, 2008.

0 poder simbólico. Rio de Janeiro: Bertrand Brasil, 2010.

BRANDÃO, Zaia. Operando com conceitos: com e para além de Bourdieu. Educação e Pesquisa, São Paulo, v. 36, n. 1, p. 22741, jan./abr. 2010.

BRASIL. Ministério da Educação. Plano Nacional de Pós-Graduação (PNPG) 2005-2010. Brasília: CAPES, dez. 2004.

CAPES. Coordenação de Aperfeiçoamento de Pessoal de Nível Superior. Disponível em: <http://www.capes.gov.br>. Acesso em: 10 maio 2011.

Portaria nº 76, de 14 de abril de 2010. Diário Oficial da União, Brasília, 19 abr. 2010.

CHOULIARAKI, Lilie; FAIRCLOUGH, Norman. Discourse in late modernity: rethinking critical discourse analysis. Edimburgo: Edinburgh University Press, 1999.

CNPq. Conselho Nacional de Desenvolvimento Científico e Tecnológico. Disponível em: <http://www.cnpq.br>. Acesso em: 10 maio 2011.

CORRÊA, Guilherme Torres. Formação pedagógica no ensino superior: um olhar sobre os mestrados e os doutorados acadêmicos em Saúde Coletiva. Dissertação (Mestrado) - Programa de Pós-Graduação em Educação em Ciências e Saúde, Núcleo de Tecnologia Educacional para a Saúde, Universidade Federal do Rio de Janeiro, Rio de Janeiro, 2012.

CUNHA, Maria Isabel da. Trajetória e lugares da formação do docente da educação superior: do compromisso individual à responsabilidade institucional. Revista Brasileira de Formação de Professores, v. 1, n. 1, p. 110-128, mai. 2010.

CUNHA, Maria Isabel da et al. As políticas públicas de avaliação e docência: impactos e repercussões. In: CUNHA, Maria Isabel (Org.). Formatos avaliativos e concepção de docência. Campinas: Autores Associados, 2005. p. 5-48.

FAIRCLOUGH, Norman. Analysing discourse: textual analysis for social research. Londres: Routledge, 2003.

A dialectical-relational approach to critical discourse analysis in social research. In: WODAK, Ruth; MEYER, Michael (Eds.).

Methods of critical discourse analysis. 2. ed. Londres: Sage Publications, 2009. p. 162-187.

FERNANDES, Cleoni Maria Barboza. Docência universitária e os desafios da formação pedagógica. Interface - Comunicação, 
Saúde, Educação, Botucatu, v. 5, n. 9, p. 177-182, ago. 2001.

FREIRE, Paulo. Pedagogia da autonomia: saberes necessários à prática educativa. 34. ed. São Paulo: Paz e Terra, 1996.

ISAIA, Silvia Maria de Aguiar. Desafios à docência superior: pressupostos a considerar. In: RISTOFF, Dilvo; SEVEGNANI, Palmira (Orgs.). Docência na educação superior. Brasília: Inep, 2006. (Coleção Educação Superior em Debate, v. 5).

LIBÂNEO, José Carlos. Conteúdos, formação de competências cognitivas e ensino com pesquisa. In: PIMENTA, Selma Garrido; ALMEIDA, Maria Isabel de (Orgs.). Pedagogia universitária: caminhos para a formação de professores. São Paulo: Cortez, 2011. p. 188-212.

MARTINS, Carlos Benedito. A formação do sistema nacional de pós-graduação. In: SOARES, Maria Susana Arrosa (Org.). A educação superior no Brasil. Porto Alegre: Instituto Internacional para a Educação Superior na América Latina e no Caribe/ UNESC0, 2002. p. 69-87.

MASETTO, Marcos Tarciso. Professor universitário: um profissional da educação na atividade docente. In: MASETTO, Marcos Tarciso (Org.). Docência universitária. 10. ed. Campinas: Papirus, 2009. p. 9-26.

NEVES, Maria Helena de Moura. Gramática de usos de português. 2. ed. São Paulo: Editora UNESP, 2011.

PIMENTA, Selma Garrido; ANASTASIOU, Lea das Graças Camargo. Docência no ensino superior. São Paulo: Cortez, 2008.

SOARES, Sandra Regina; CUNHA, Maria Isabel da. Programas de pós-graduação em educação: lugar de formação da docência universitária? Revista Brasileira de Pós-Graduação, Brasília, v. 7, n. 14, p. 577-604, dez. 2010.

THIRY-CHERQUES, Hermano Roberto. Pierre Bourdieu: a teoria na prática. Revista de Administração Pública, Rio de Janeiro, v. 40, n. 1, p. 27-55, jan./fev. 2006.

Recebido em: 22.05.2012

Aprovado em: 06.02.2013

Guilherme Torres Corrêa é mestre em Educação em Ciências e Saúde pela Universidade Federal do Rio de Janeiro (UFRJ), doutorando em Educação na Universidade de São Paulo (USP) e membro do Grupo de Estudos e Pesquisas sobre a Formação do Educador.

Victoria Maria Brant Ribeiro é doutora em Educação pela Universidade Federal do Rio de Janeiro (UFRJ), professora associada e pesquisadora do Programa de Pós-Graduação em Clínica Médica da mesma universidade. 